\title{
Results of Caring and Reaching for Health (CARE): A Cluster-Randomized Controlled Trial Assessing a Worksite Wellness Intervention for Child Care Staff
}

Laura A Linnan ( $\sim$ linnan@email.unc.edu )

Department of Health Behavior, Gillings School of Global Public Health, University of North Carolina at Chapel Hill https://orcid.org/0000-0002-8702-4624

\section{Amber E Vaughn}

Center for Health Promotion and Disease Prevention, University of North Carolina at Chapel Hill

\section{Falon Smith}

University of North Carolina at Chapel Hill https://orcid.org/0000-0002-0849-1161

\section{Philip Westgate}

Department of Biostatistics, College of Public Health, University of Kentucky

\section{Derek Hales}

Center for Health Promotion and Disease Prevention, University of North Carolina at Chapel Hill

\section{Gabriela Arandia}

Department of Health Behavior, Gillings School of Global Public Health, University of North Carolina at Chapel Hill

\section{Cody Neshteruk}

Department of Nutrition, Gillings School of Global Public Health, University of North Carolina at Chapel Hill

\section{Erik Willis}

University of North Carolina at Chapel Hill Libraries

\section{Dianne S. Ward}

Department of Health Behavior, Gillings School of Global Public Health \& Center for Health Promotion and Disease Prevention, University of North Carolina at Chapel Hill

\section{Research}

Keywords: worksite, worker health, child care, physical activity

Posted Date: December 16th, 2019

DOI: https://doi.org/10.21203/rs.2.18643/v1

License: (c) (1) This work is licensed under a Creative Commons Attribution 4.0 International License. Read Full License

Version of Record: A version of this preprint was published at International Journal of Behavioral Nutrition and Physical Activity on May 15th, 2020. See the published version at https://doi.org/10.1186/s12966-020-00968-x. 


\section{Abstract}

\section{Background}

Child care workers are among the lowest paid US workers and experience a wide array of health concerns. The physical and mental demands of their job and the lack of employer-provided health-insurance increase health risks. The Caring and Reaching for Health (CARE) study evaluated a 6-month Healthy Lifestyles intervention targeting child care workers' physical activity (primary outcome), other health behaviors, and their workplace health environment.

\section{Methods}

Eligible child care centers, defined as being in operation for at least two years and employing a least four staff, were enrolled into CARE's cluster-randomized trial. Centers and their child care staff were randomly assigned to either the Healthy Lifestyles (HL) intervention arm or the Healthy Finances (HF) attention control arm using a block randomization approach. Outcome measures were collected during center visits at baseline and immediately postintervention by trained data collectors blinded to center arm assignment. Workers' physical activity was assessed with accelerometers, worn for seven days. Secondary outcome measures included biometric assessments of health and fitness, web-based surveys about health behaviors, and an environmental audit of workplace supports for health. Multi-level linear mixed models assessed worker- and center-level changes in these outcomes.

\section{Results}

Participants included 553 child care workers representing 56 centers $(\mathrm{HL}=250$ staff $/ 28$ centers, $\mathrm{HF}=303$ staff $/ 28$ centers). At six months, moderate-to-vigorous physical activity declined slightly in both arms (-1.3 minutes/day, 95\% $\mathrm{Cl}$ - $-3.0,0.3$ in $\mathrm{HL} ;-1.9$ minutes/day, $95 \% \mathrm{Cl}-3.3,-0.5 \mathrm{in} \mathrm{HF)}$, but there was no significant group by time interaction. Several secondary outcomes for other health behaviors and workplace health environment showed improvements in favor of the intervention arm, yet differences did not remain statistically significant after adjustment for multiple comparisons.

\section{Conclusions}

While the Healthy Lifestyles intervention did not improve health behaviors or the workplace health environment, results confirmed the pressing need to focus on the health of child care workers. Future interventions should focus on prevalent health issues (e.g., weight, stress), include both high-tech and high-touch intervention strategies, and address work conditions or other social determinants of health (e.g. wages) as a means of improving the health of these important workers.

\section{Introduction}

Low-wage workers are among the fastest growing segments in the United States workforce [1], and they suffer disproportionately from both health behavioral risks factors and chronic diseases that are the leading causes of premature death and disability $[2,3]$. While workplace health promotion interventions have achieved some encouraging results on a wide array of behavioral risk factor outcomes such as physical activity, diet, and weight management [4-7]; there is a critical need to develop effective interventions to address the health of low-wage workers [8].

Child care workers are among the lowest paid employees, earning a median hourly wage of $\$ 10.72$ [9], which is well below the recommended living wage of $\$ 16$ per hour [10]. Not surprisingly, there is growing evidence that child care 
workers' have heightened prevalence of overweight and obesity, high blood pressure, and diabetes [11-14], placing them at higher risk for many debilitating chronic diseases.

Recently, several advocacy groups have called attention to the health of child care workers. In 2012, Child Care Aware published "Paths to a Healthier Child Care Workforce," which reported on child care workers' poor physical activity and dietary habits, identified critical barriers to health and wellness, and suggested health-supportive improvements to the workplace [15]. In 2017, the National Head Start Association released its "Nurturing Staff Wellness Toolkit," which offered guidance for establishing a staff wellness program and checklist of critical components to include [16].

Despite recognition that child care workers need workplace health promotion efforts, few rigorous evaluations of these efforts exist. Gosliner et al. (2010) conducted a 9-month quasi-experimental study with 13 child care centers in low-income neighborhoods in northern California, and evaluated the impact of adding a worksite wellness program to a training and technical assistance intervention focused on children's health and nutrition [17]. The worksite wellness program consisted of a kick-off training, monthly newsletters promoting nutrition and physical activity, a walking program, and follow-up visits from intervention staff. Results indicated a modest impact on child care workers' health behaviors-no significant effect on physical activity and only a small, but significant reduction in sugar sweetened beverage intake. However, the program successfully improved the child nutrition environment and the self-efficacy of staff to communicate with parents about child health. This study was limited by its small sample size $(n=82)$, high staff turnover (23\%), and a lack of objective measure of physical activity, health environments and workplace supports.

Another study, completed by Herman et al (2017) with 75 Head Start sites across five states, evaluated the effectiveness of the "Eat Healthy, Stay Active!" curriculum, a 6-month educational intervention promoting healthier nutrition and increased physical activity among child care workers, parents, and children [18]. Child care workers from these Head Start sites were given materials designed to increase their knowledge of obesity prevention strategies. Information covered dietary guidelines, budget-friendly shopping tips, and ideas for incorporating physical activity into daily routines. Additionally, staff were trained on a core curriculum that they then delivered to parents and children. Curriculum topics included diabetes awareness, obesity prevention, nutrition education, healthy eating on a budget, and physical activity. Results demonstrated a significant reduction in child care workers' body mass index (BMI) and the percent of workers classified as obese. Significant improvements were also observed in diet and physical activity knowledge and behaviors, but unfortunately, child care worker and parent data for these latter outcomes were reported together. While promising, there was no comparison or control group in this study and outcomes relied only on unvalidated self-report nutrition and physical activity measures.

These studies had important limitations and both evaluated interventions with a primary target of child health where the child care workers served primarily as key deliverers (not targets) of the intervention. The purpose of the Caring and Reaching for Health (CARE) study was to explore whether a multi-level, theory-guided intervention targeting the child care worker (and the workplace), could improve the health of child care workers. Specifically, this study evaluated the effectiveness of a "Healthy Lifestyles" intervention on child care workers' physical activity (primary outcome), as well as diet, tobacco and e-cigarette use, sleep, stress, health and biometric indicators (e.g., BMI, blood pressure, cardiovascular fitness, muscle strength), and the workplace health and safety environment (e.g., infrastructure, policies and procedures, programs and promotions, physical environment) compared to an attention control "Healthy Finances" intervention. Study results, as well as implications and recommendations for future worksite-based efforts for child care workers are presented in this paper.

\section{Methods}


The CARE study used a two-arm, cluster-randomized trial to test the effectiveness of a "Healthy Lifestyles" intervention compared to a "Healthy Finances" attention control program. The study was conducted between 2015 and 2018. The study design and protocols for CARE [19] as well as a complete description of the Healthy Lifestyles intervention [20] have been described in accordance with SPIRIT and TIDieR guidelines and published elsewhere. All protocols were approved by the Institutional Review Board at the University of North Carolina at Chapel Hill and registered at www.ClinicalTrials.gov (NCT02381938).

\section{Participants}

A total of 553 child care workers from 56 child care centers located in central North Carolina participated in the study[19]. A multi-phase recruitment strategy was employed to recruit participants in four waves. Community partners helped introduce child care centers to the study by distributing announcements through existing communication channels and offering group informational sessions. The research team followed-up by phone with centers that expressed interest to review study details and confirm eligibility. In addition, the research team identified child care centers through the North Carolina Division of Child Development and Early Education's public database of licensed providers [21] and sent announcements about the study directly (by mail and email). Announcements were followedup with phone calls by the research team to review study details, assess interest, and confirm eligibility. Initial eligibility criteria for centers required they employ at least four staff, have been in operation for at least two years, and have no plans to close within the next 18 months. Once initial eligibility was confirmed, research team members conducted onsite center visits to recruit child care workers. To be eligible to participate, workers had to be at least 18 years of age, able to speak and read English, and either pass the Physical Activity Readiness Questionnaire (PAR-Q) screening or obtain medical permission to participate [22]. At least four workers (one administrator and three staff) had to agree to participate and sign consent for the center to be remain eligible. In addition, at least three workers (one administration and two staff) had to attend the kick-off event for the center to remain in the study and be randomized.

\section{Randomization}

Workers were randomized in clusters, based on the center where they were employed. Randomization occurred at a kick-off event, which followed baseline data collection. During these events, each center representative selected an envelope from a bowl, and the card within revealed their assignment - Healthy Lifestyles or Healthy Finances. Cards were produced based on randomization tables (generated by the study statistician) created using a block randomization approach employing a block size of two to ensure balance in the number of centers in each study arm in each wave. Results of randomization were immediately announced. Participating centers (and workers who attended the kickoff event) then adjourned to separate locations to participate in a workshop based on their assignment to Healthy Lifestyles or Health Finances.

\section{Intervention: Healthy Lifestyles}

The Healthy Lifestyles intervention has been described in detail elsewhere using TIDieR guidelines [19, 20]. Healthy Lifestyles was a six-month, multi-level, theory-guided intervention designed to increase physical activity and improve other health behaviors among child care workers. The intervention focused on increasing support for health promotion at three levels: intrapersonal (individual workers), interpersonal (interactions between co-workers), and organizational (the child care center). Strategies employed to target each level were informed by: Perceptual Control Theory (intrapersonal) [23, 24], Social Support Theory (interpersonal) [25], and Diffusion of Innovation (organizational) [26]. 
The intervention began with a kick-off event, which consisted of a 2-hour morning health and wellness fair integrating a variety of local community organizations and resources along with baseline assessments and a 1.5-hour afternoon educational workshop led by the study interventionist. The morning portion was attended by all participants, and randomization occurred at lunchtime. The afternoon arm-specific educational workshop introduced workers to the upcoming campaigns (Healthy Lifestyle or Healthy Finance) and the related intervention components. In the months that followed, staff participated in three successive 8-week campaigns. At the start of each campaign, centers received informational magazines to distribute to workers and materials for center displays including team activity planners.

For Healthy Lifestyles, workers were asked to set two health behavior goals - one on physical activity (e.g., getting 10,000 steps per day) and one other health behavior (i.e., increasing fruit and vegetable intake, limiting snack foods, eliminating sugar-sweetened beverages, limiting fast food, eliminating cigarette use, improving sleep, strength training or daily self-weighing). To facilitate monitoring of physical activity (i.e., steps), each worker received a pedometer. Workers were encouraged to self-monitor these behaviors every day and submit information weekly using the CARE website. Workers received tailored feedback based on this self-monitoring information and goals were adjusted accordingly (e.g., if steps goal for previous week was met, new goal would increase the steps target). Workers also received weekly email/text prompts to remind them to submit their self-monitoring information and biweekly (every other week) prompts to be active. By the end of wave 1's first campaign, website data showed that many workers were not monitoring their behaviors. So, a center visit was added during the first week of each campaign to encourage workers to use their pedometer and log their activity, giving special attention to workers that had not been monitoring. This modification to our intervention protocol was then implemented in all 4 waves. Prizeraffles were offered as incentives for self-monitoring and goal attainment.

During each campaign, the center director received technical assistance and coaching from the study interventionist focused on critical elements of workplace health promotion. Originally, this component was designed to be delivered as a group webinar. After scheduling difficulties and lack of attendance in wave 1, delivery was modified to offer directors individual coaching calls.

\section{Attention Control: Healthy Finances}

The Healthy Finances program was designed to provide a similar level of attention as the Healthy Lifestyles arm, including three, 8-week campaigns with similar components (e.g. magazines, center displays, email/text prompts, prize raffles). The critical difference was that all messages focused on workers' financial well-being and financial success of the center. Instead of goal-setting and self-monitoring health behaviors, workers were encouraged to take quizzes about the new financial management strategies they learned. Instead of live technical assistance and coaching, center directors were offered pre-recorded webinars on budgeting, marketing strategies for their child care program, and managing legal risk specifically designed for use by child care programs.

\section{Outcome Measures}

Outcome measures were collected at three timepoints-baseline, post-intervention, and maintenance (one-year postintervention)-during onsite center visits conducted by trained data collectors blinded to center arm assignment. A full 
description of data collection protocols and measurement tools is described in detail elsewhere [19]. This paper reports on baseline to immediate post-intervention results only.

Primary Outcome. Physical activity was assessed using ActiGraph GT3X (ActiGraph, LLC, Pensacola, FL) accelerometers, which workers wore for seven consecutive days. Workers received monitors during center visits along with a postage-paid envelope for their return. Accelerometer data were downloaded using ActiLife software then processed to assess wear and non-wear time. Only participants with valid wear time (i.e., $\geq 7$ hours of wear time on $\geq 4$ days) were included in the primary analysis. Adult-specific cut points were then applied to compute minutes of moderate-to-vigorous physical activity (MVPA, $\geq 2020 \mathrm{cmp}$, primary outcome), lifestyle physical activity ( $\geq 760 \mathrm{cpm}$ ), and sedentary time $(\leq 100 \mathrm{cpm})$ each day $[27,28]$. Daily estimates from all valid days of wear were used to calculate average minutes per day for each level of physical activity. To account for variations in wear time, estimates were standardized to a 14-hour day. Weekday and weekend day data were also identified and used to calculate average weekday and weekend minutes per day of MVPA.

Secondary Outcomes. Workers' health behaviors were self-reported using the Carolina Health Assessment and Research Tool (CHART) [29]. This web-based survey is divided into modules, each of which captures a specific health behavior. CHART was modified for this project to include modules on physical activity, diet, tobacco and e-cigarette use, sleep, and emotional health. CHART also included a demographics module that captured participant demographics and center characteristics. Original CHART items and all modifications drew from existing measures [30-35], as described in detail elsewhere [19]. Drawing on procedures used in source measures, CHART data were summarized to describe health behaviors, specifically times per week of muscle strengthening activities; servings per day of fruit (excluding juice), vegetables, (excluding potatoes), fruits and vegetables (excluding fruit juice and potatoes), sugar sweetened beverages, salty snacks, and fast food; eating habits score (scores range from 0 to 20 , higher scores indicates healthier eating habits); current smoking status (smoker or non-smoker) and e-cigarette use (ever used or never used); hours per night of sleep and sleep quality (bad or good); and level of distress (ratings range from 0 to 10, higher scores indicate higher distress).

Biometric assessments of health and fitness indicators were taken by trained data collectors using established protocols. These measures included height, weight, and waist circumference[36]; blood pressure [37]; the six-minute walk test [38]; hand grip [39]; the 30-second chair sit and stand test [40, 41]; and the four-stage balance test [42, 43]. Height and weight measurements were used to calculate BMI. Blood pressure readings were used to calculate mean arterial pressure.

The workplace health and safety environment was assessed using a tool developed specifically for this study [19], but drawing from existing workplace environmental assessments [44-46]. Information was collected primarily through a structured interview with the director and an environmental observation conducted by data collectors. A scoring rubric was guided by a recent review existing measures of workplace environmental and policy supports for physical activity and healthy eating [47]. Data were then used to calculate scores for four domains: general infrastructure (possible range $0-27$ ), organization policies and procedures (possible range $0-35$ ), programs and promotions (possible range 0 65), and internal physical environment (possible range 0-27). Higher scores always indicated greater support for staff health and safety. For the latter three domains-organization policies and procedures, programs and promotions, and internal physical environment-component scores were also calculated to look at supports available for physical activity (possible range of scores being $0-7,0-7$, and $0-5$, respectively) and nutrition (possible range of scores being 0 5, 0-9, and 0-11, respectively). 
To document delivery and participation in the intervention, process evaluation measures (dose delivered and received) were collected throughout the study using a combination of direct observation, surveys, and field notes. In addition, a small sample of participants $(n=30)$ from the intervention group were interviewed at the conclusion of the study to reflect on their experience.

\section{Statistical Analysis}

Descriptive statistics were used to summarize baseline demographic data for workers and centers in the intervention and control arms. Then, intent to treat (ITT) analyses were performed using all randomized participants. Missing data were addressed using maximum likelihood estimation under the assumption of missing at random. Analyses used multi-level linear mixed models (SAS PROC MIXED) for continuous outcomes and GEE-based marginal logistic regression (SAS PROC GLIMMIX) for binary outcomes to examine group differences of primary and secondary outcomes. Models included random cluster effects to account for covariance between participants within the same center as well as fixed effects for time, trial arm, time $\mathrm{x}$ arm interaction, and study wave (stratification variable during randomization). An unstructured working covariance was used to account for statistical covariance among repeated measurements from the same subject. The residuals of all continuous outcome variables were checked for normality. Where evidence of departure from normality was apparent the square root of the outcomes were used for analyses in order to obtain valid p-values; however, results are presented in their original scale for ease of interpretation.

To assess the impact of missing data, sensitivity analyses were conducted using multiple imputation (SAS PROC MI). Missing data were imputed 50 times for all outcome variables using variables associated with drop-out, demographic variables to be included in later regression analyses, and an indicator for child care center to account for the possibility of clustering. Analyses used linear mixed ANCOVA models to examine change in continuous outcomes and GEE-based marginal logistic regression for binary outcomes. Similar to the ITT analyses, models included random cluster effects to account for covariance between participants within the same center as well as study wave. Models were additionally adjusted for the baseline value of the given outcome variable as well as demographic characteristics identified a priori based on evidence of their predictive value for physical activity and other health behaviors (i.e., age, race, income, baseline BMI). Inferential results based on the imputed data were obtained via SAS PROC MIANALYZE. All tests were two-sided at the 0.05 level. Multiple comparisons for all secondary intervention effects were accounted for by using the false discovery rate method (i.e., the expected proportion of Type I errors among significant findings) to obtain adjusted p-values. All analyses were performed using SAS Software, version 9.4 (SAS Institute Inc., Cary, NC).

\section{Results}

\section{Participant Characteristics}

The study's CONSORT diagram is presented in Figure 1. Across four waves of recruitment, 704 workers representing 74 child care centers were recruited and measured. Of those, 553 workers (78\%) were randomized, resulting in 250 workers from 28 centers in the intervention arm and 303 workers from 28 centers in the control arm. The loss of participants between baseline measurement and randomization was anticipated as the study had intentionally included a run-in period that required baseline measurement and center attendance at the kick-off event for a center to be randomized.

Baseline characteristics of participating workers and child care centers are presented in Table 1. Across intervention and control arms, workers were predominantly female (97\%) and either African American (51\%) or white (37\%). Forty percent of workers had a household income less than $\$ 20,000$ (placing them at or below the federal poverty level for a 
family of three). Most workers described themselves as staff (82\%) versus center administrator. On average, centers employed 15 staff and served 66 children. Centers had, on average, a quality rating of 4.3 stars (based on a rating system of 1-5 stars). In addition, most centers accepted subsidies (96\%, financial support for low-income children's enrollment fees) and were enrolled in the Child and Adult Care Food Program (86\%, reimbursement for meals/snacks served to low-income children).

Post-intervention measures were collected on 463 workers (84\%), including 203 workers (81\%) in the intervention arm and 260 workers (86\%) in the control arm. A comparison of completers versus non-completers revealed that noncompleters tended to be younger, lower income, uninsured, and describe themselves as staff. Non-completers also had slightly better health profiles compared to completers (e.g., lower weight, waist circumference, and blood pressure; more steps per day).

\section{Primary Outcome - Physical Activity}

Results of the ITT analyses are presented in Table 2 (for all worker-level outcomes). At baseline, MVPA was significantly lower among participants in the intervention group (16.0 \pm 13.4 minutes/day; $p=0.02)$ compared to those in the control group (18.6 \pm 14.8 minutes/day). Small but significant within group decreases in MVPA were observed in both the intervention group ( -1.3 minutes/day, $p=0.04)$ and control group $(-1.9$ minutes/day, $p=0.001)$ from baseline to post-intervention. There was no significant between group difference for change in MVPA $(p=0.57)$. Analyses with imputed datasets did not alter results.

There were no significant within or between group differences for change in sedentary activity, lifestyle physical activity, or weekend MVPA. Small but significant within group decreases were seen in weekday MVPA in both the intervention group (-1.9 minutes/day, $p=0.04)$ and control group ( -2.9 minutes/day, $p<0.001)$ from baseline to postintervention. Odds of meeting physical activity recommendations also significantly decreased within both the intervention group $(-37 \%, 95 \% \mathrm{Cl}, 8-66 \%)$ and control group $(-31 \%, 95 \% \mathrm{Cl}, 7-48 \%)$ from baseline to post-intervention. In contrast, small but significant within group increases were seen in days per week of muscle strengthening activities in both the intervention group $(0.7$ times/week, $p<0.001)$ and control group $(0.5$ times/week, $p<0.001)$. There were no significant between group differences in these additional physical activity outcomes. Analyses with imputed data did not change these results.

\section{Secondary Outcomes}

Health behaviors. Prior to adjustment for multiple comparisons, significant modest improvements in several healthrelated behaviors were observed from baseline to post-intervention in the intervention group compared to the control group. Improvements included intake of fruits and vegetables ( +0.3 times/day, $p<0.01)$, sugar sweetened beverages (-0.3 times/day, $p=0.04)$, eating out $(-0.1$ times/day, $p<0.01)$, and overall eating habits score $(+0.9$ points, $p<0.01)$. Similarly, hours of sleep/night $(+0.3$ hours/day, $p<0.046)$ and smoking status $(O R=0.60, p=0.03)$ showed modest, but statistically significantly improvements from baseline to post-intervention in the intervention vs. control group. After adjusting for multiple comparisons, these between group differences were no longer significant. Analyses with imputed data showed significant improvement in only dietary intake of salty snacks $(-0.3$ times/day, $p=0.016)$ in the intervention group compared to the control group. Once again, differences were no longer significant after adjusting for multiple comparisons.

Workplace health and safety. Workplace health and safety results using ITT analyses are presented in Table 3. Prior to adjustment for multiple comparisons, there were significant increases in the physical activity component scores in both the organization policies and procedures domain $(p=0.048)$ and the programs \& promotions domain $(p=0.01)$ in 
favor of intervention centers. However, these between group differences were no longer significant after adjusting for multiple comparisons. In analyses with imputed data, only the change in physical activity component score for the programs and promotions domain was significant $(\mathrm{p}=0.02)$, until adjusted for multiple comparisons.

\section{Process Evaluation}

Process evaluation data are presented in Table 4, confirming that the intervention was delivered as intended. However, workers' engagement with various intervention components was low.

\section{Discussion}

\section{DISCUSSION}

The CARE study is the first randomized controlled trial of a workplace health promotion intervention focusing on the health of the child care workers and their workplace environment. The Healthy Lifestyles intervention targeted multiple levels of influence and integrated theory to inform strategies used at each level, yet it failed to improve physical activity, the primary target. In fact, workers in both groups has slightly decreased levels of physical activity.

Workers in the Healthy Lifestyles intervention had significant improvements in several dietary variables (i.e., fruit and vegetables, sugar sweetened beverages, eating out, and overall eating habits score) and a decreased odd (34\%) of smoking. These results were similar to those observed in our pilot [20]. While encouraging, results must be interpreted with caution as they were no longer statistically significant after adjusting for multiple comparisons and in sensitivity analyses using imputed data.

Clearly, the Healthy Lifestyles intervention was not effective in producing significant improvements in the primary outcome (physical activity), which warrants consideration of several other plausible explanations: a potential lack of engagement among workers with critical intervention components, the lack of intervention intensity, quality or duration, or the inability of workers to overcome competing demands. With regard to lack of engagement, our process evaluation data demonstrated that child care workers did not consistently engage in self- monitoring, a critical component of the intervention. While $72 \%$ of workers in the Healthy Lifestyles arm logged their steps at least once, far fewer logged the steps regularly as only $44 \%$ qualified for raffle entry (which required regular monitoring). Thus, lack of engagement may have been problematic.

It is also possible that the intervention had insufficient intensity, quality or duration. The six-month intervention duration was effective in previous studies [49], but post-intervention interviews with child care workers revealed a strong desire for more personal interaction, which would have created a more "intensive" and "high-touch" intervention including more personal communications or additional events with coworkers or research staff like the initial kickoff event. The center visuals were intended to leverage social support from coworkers by promoting team building and group physical activity. However, center visuals were displayed in only $67 \%$ of centers, and often were taken down following the first campaign. Child care workers need more assistance from research staff to utilize these center visuals to their full potential.

Another potential explanation for the lack of change in physical activity is that child care workers face serious competing demands which limit physical activity that our Healthy Lifestyles intervention could not overcome. As emphasized in a white paper produced by Child Care Aware, child care workers report being very tired at the end of the day, having limited time, and facing a number of competing after-work responsibilities (e.g., caring for their own 
children, preparing meals, maintaining the household), as well as being unable to afford memberships in fitness centers and gyms [15]. Baseline levels of stress among child care workers in this study were significantly higher than stress levels among the general population $[11,19]$. Compounding any of these challenges is the fact that these are low wage workers in a physically demanding job. Thus, any or all of these reasons may explain why the Healthy Lifestyles intervention did not produce intended improvements in physical activity among child care workers in this study.

Despite a lack of effect on the individual worker level, results showed some promising changes in workplace supports for physical activity, particularly in policies, procedures, programs, and promotions. These environmental changes align well with the content of the coaching sessions which encouraged center directors to expand opportunities to support physical activity through group activities, education, and policy changes. The content of the coaching calls were also consistent with several of the essential elements for staff wellness recommended by the National Head Start Association, such as identifying a wellness leader, assigning a wellness committee, and offering engaging wellness activities [16]. However, the three coaching calls offered as part of Healthy Lifestyles may not have been enough to focus on other recommended elements, such as conducting a detailed needs assessment, identifying useful resources and partnerships, communicating effectively, and having a continuous evaluation plan [45].

Results of this study and similar recent workplace trials $[6,7]$ suggest that improving workers' health will require a more comprehensive approach that addresses not only health behaviors but also the work environment, working conditions, benefits and compensation [48-50]. Child care workers are confronted with many challenges on a daily basis from both their job and life that may leave them little discretionary time or energy to focus on their health. Providing health benefits and/or improving compensation and wages of these important members of the workforce may provide a more direct and lasting pathway to improved health than health promotion alone. Otten et al. (2019) are studying the effects of a policy to improve wages among child care workers in Seattle [51]. Their baseline findings reiterate the poor benefits and lack of compensation as well as the emotional strains and societal disrespect experienced by these workers [51]. In this study with low wage child care workers, it is interesting that the Healthy Finances intervention which focused on budgeting, securing credit, and managing personal finances appeared equally effective in reducing stress as did the Healthy Lifestyles intervention which included content on traditional stress management techniques. Given the growing body of literature documenting the high prevalence of stress and depression among child care workers [11, 14,51,52], future research is warranted on the underlying causes of child care worker stress (including from the work environment), the ways in which stress can be reduced, and the impact of stress reduction on overall health. A Total Worker Health approach [53-55] that addresses both working conditions (e.g. wages, work schedules, etc.) and health behaviors may be more impactful than traditional health promotion activities, particularly for low-wage workers like those in child care [56, 57].

\section{Strengths and limitations}

This study had many strengths, including the use of a multi-level, theory-guided intervention that had been previously proven effective in pilot-testing, an attention control (Healthy Finances) group, an objective assessment of physical activity (accelerometry), and, a rigorous analytic approach. Although not a limitation per se, the use of conservative analytic approaches (e.g., intent-to-treat analysis, controlling for potential confounders) can minimize effect sizes [58]. Since centers were recruited from seven counties in NC, results cannot be generalized to all child care centers in the state or nation. Further, the intervention was delivered to a child care workers who volunteered to participate, and thus, may not be representative of all child care workers. Despite these issues, the many study strengths outweigh its limitations, particularly in light of the fact that this was among the very first trials addressing the health of child care workers. 


\section{Conclusions}

We conducted one of the first and most rigorous evaluations of a multi-level, theory-guided intervention designed to increase physical activity among child care workers. There were some encouraging, albeit modest, positive changes documented at the child care worker level on muscle strengthening activities and several secondary health behavior outcomes (e.g. eating behaviors, sleep and tobacco use), but not on the primary physical activity outcome. There were also some positive changes at the center level in terms workplace supports for physical activity. However, results often did not remain significant after adjusting for multiple comparisons or using multiple imputation to address missing data. To help promote physical activity and improve the health and well-being of child care workers, future research should consider interventions that addressing a Total Worker Health approach involving the worker, working conditions and the larger social context in which the child care worker exists.

\section{Declarations}

\section{Ethics approval and consent to participate}

Written informed consent was obtained from all study participants and all protocols were approved by the Institutional Review Board at the University of North Carolina at Chapel Hill and registered at www.ClinicalTrials.gov (NCT02381938).

\section{Consent for publication}

Not applicable

\section{Availability of data and materials}

Datasets used and/or analyzed during the current study are available from the corresponding author on reasonable request provided the investigator who proposes to use the data has approval from an Institutional Review Board (IRB), Independent Ethics Committee (IEC), or Research Ethics Board (REB), as applicable, and executes a data use/sharing agreement with UNC.

\section{Competing interests}

The authors declare that there are no known conflicts of interest associated with this publication.

\section{Funding}

This project was funded by the National Heart, Lung, And Blood Institute of the National Institutes of Health (NIH) under award number R01HL119568. The project was conducted out of the University of North Carolina at Chapel Hill at the Center for Health Promotion and Disease Prevention, a Prevention Research Center funded through a cooperative agreement with the Centers for Disease Control and Prevention (CDC, U48-DP001944). Findings and conclusions in this article are those of the authors and do not necessarily represent the official position of the NHLBI, $\mathrm{NIH}$, or CDC.

\section{Authors' contributions}

Laura Linnan, Dianne Ward, and Amber Vaughn conceived and designed the study. Falon Smith led data collection and processing. Derek Hales was responsible for the processing of accelerometer data. Phillip Westgate, Erik Willis, and Cody Neshteruk undertook statistical/data analysis and were responsible for interpretation of analysis results. 
Laura Linnan, Amber Vaughn, Falon Smith, Gabriela Arandia, and Dianne Ward drafted the manuscript. Laura Linnan, Dianne Ward, and Amber Vaughn obtained funding to carry out the study. All authors were involved in reviewing the manuscript and provided approval of the final version of this article.

\section{Acknowledgements}

We would like to acknowledge the child care workers and centers that participated in the study as well as Lori Bateman (project manager), Ellie Morris (study interventionist), research assistants, and data collectors.

\section{Abbreviations}

ANCOVA

analysis of covariance

BMI

body mass index

CARE

Caring And Reaching for Health

Carolina Health Assessment and Research Tool

GEE

generalized estimating equation

ITT

intent to treat

MVPA

moderate-to-vigorous physical activity

PARQ

Physical Activity Readiness Questionnaire

Keywords

worksite; worker health; child care, physical activity

\section{Abbreviations}

ANCOVA: analysis of covariance

BMI: body mass index

CARE: Caring And Reaching for Health

CHART: Carolina Health Assessment and Research Tool

GEE: generalized estimating equation

ITT: intent to treat

MVPA: moderate-to-vigorous physical activity

PARQ: Physical Activity Readiness Questionnaire

\section{References}


1. Stiehl E, Shivaprakash N, Thatcher E, Ornelas IJ, Kneipp S, Baron SL, et al. Worksite Health Promotion for LowWage Workers: A Scoping Literature Review. Am J Health Promot. 2018;32(2):359-73. doi:

$10.1177 / 0890117117728607$

2. Kanjilal S, Gregg EW, Cheng YJ, Zhang P, Nelson DE, Mensah G, et al. Socioeconomic status and trends in disparities in 4 major risk factors for cardiovascular disease among US adults, 1971-2002. Arch Intern Med. 2006;166(21):2348-55. doi: 10.1001/archinte.166.21.2348

3. Singh GK, Siahpush M. Widening socioeconomic inequalities in US life expectancy, 1980-2000. Int J Epidemiol. 2006;35(4):969-79. doi: 10.1093/ije/dyl083

4. Osilla KC, Van Busum K, Schnyer C, Larkin JW, Eibner C, Mattke S. Systematic review of the impact of worksite wellness programs. Am J Manag Care. 2012;18(2):e68-81.

5. Task Force on Community Preventive Services. Recommendations for worksite-based interventions to improve workers' health. Am J Prev Med. 2010;38(2 Suppl):S232-6. doi: 10.1016/j.amepre.2009.10.033

6. Song Z, Baicker K. Effect of a Workplace Wellness Program on Employee Health and Economic Outcomes: A Randomized Clinical Trial. JAMA. 2019;321(15):1491-501. doi: 10.1001/jama.2019.3307

7. Jones D, Molitor D, J. R. What do workplace wellness programs do? Evidence from the Illinois Workplace Wellness Study. The National Bureau of Economic Research. 2018.

8. Baron SL, Beard S, Davis LK, Delp L, Forst L, Kidd-Taylor A, et al. Promoting integrated approaches to reducing health inequities among low-income workers: applying a social ecological framework. Am J Ind Med. 2014;57(5):539-56. doi: 10.1002/ajim.22174

9. Bureau of Labor Statistics, U.S. Department of Labor. Occupational Outlook Handbook. https://www.bls.gov/ooh/home.htm.

10. Nadeau CA G, AK. Bare Facts About the Living Wage in America 2017-2018. Massachusetts Institute of Technology. 2018 http://livingwage.mit.edu/articles/31-bare-facts-about-the-living-wage-in-america-2017-2018. Accessed June 14, 2019.

11. Linnan L, Arandia G, Bateman LA, Vaughn A, Smith N, Ward D. The Health and Working Conditions of Women Employed in Child Care. Int J Environ Res Public Health. 2017;14(3). doi: 10.3390/ijerph14030283

12. Sharma S, Dortch KS, Byrd-Williams C, Truxillio JB, Rahman GA, Bonsu P, et al. Nutrition-related knowledge, attitudes, and dietary behaviors among head start teachers in Texas: a cross-sectional study. J Acad Nutr Diet. 2013;113(4):558-62. doi: 10.1016/j.jand.2013.01.003

13. Tovar A, Vaughn AE, Grummon A, Burney R, Erinosho T, Ostbye T, et al. Family child care home providers as role models for children: Cause for concern? Prev Med Rep. 2017;5:308-13. doi: 10.1016/j.pmedr.2016.11.010

14. Whitaker RC, Becker BD, Herman AN, Gooze RA. The physical and mental health of Head Start staff: the Pennsylvania Head Start staff wellness survey, 2012. Prev Chronic Dis. 2013;10:E181. doi: 10.5888/pcd10.130171

15. Child Care Aware of America. Paths to a Healthier Child Care Workforce. 2012 http://usa.childcareaware.org/wpcontent/uploads/2017/03/Staff-wellness-white-paper.pdf. Accessed March 20, 2019.

16. National Head Start Association. Nurturing Staff Wellness. Alexandria, VA. 2017 https://www.nhsa.org/nurturingstaff-wellness. Accessed March 22, 2019.

17. Gosliner WA, James P, Yancey AK, Ritchie L, Studer N, Crawford PB. Impact of a worksite wellness program on the nutrition and physical activity environment of child care centers. Am J Health Promot. 2010;24(3):186-9. doi:

10.4278/ajhp.08022719

Page $13 / 23$ 
18. Herman A, Nelson BB, Teutsch C, Chung PJ. "Eat healthy, stay active!": a coordinated intervention to improve nutrition and physical activity among head start parents, staff, and children. Am J Health Promot.

2012;27(1):e27-36. doi: 10.4278/ajhp.110412-QUAN-157

19. Ward DS, Vaughn AE, Hales D, Viera AJ, Gizlice Z, Bateman LA, et al. Workplace health and safety intervention for child care staff: Rationale, design, and baseline results from the CARE cluster randomized control trial.

Contemporary clinical trials. 2018;68:116-26. doi: 10.1016/j.cct.2018.02.018

20. Arandia G, Vaughan A, Bateman L, Ward D, Linann L. Development of a workplace intervention for child care staff: Caring and Reaching for Health's (CARE) Healthy Lifestyles intervention. Health Promot Pract. 2018. doi: $10.1177 / 1524839918786214$

21. North Carolina Division of Child Development and Early Education. Child care facility search site. http://ncchildcaresearch.dhhs.state.nc.us/. Accessed May 10, 2017.

22. Warburton DER, Jamnik VK, Bredin SSD, Gledhill N. The Physical Activity Readiness Questionnaire for Everyone (PAR-Q+) and Electronic Physical Activity Readiness Medical Examination (ePARmed-X+). Health \& Fitness Journal of Canada. 2011;4(2):3-23.

23. Powers WT. Behavior: The Control of Perception. Chicago, IL: Aldine Publishing Co.; 1973.

24. Michie S, Abraham C, Whittington C, McAteer J, Gupta S. Effective techniques in healthy eating and physical activity interventions: a meta-regression. Health Psychol. 2009;28(6):690-701. doi: 10.1037/a0016136

25. Israel BA. Social networks and social support: implications for natural helper and community level interventions. Health Educ Q. 1985;12(1):65-80.

26. Rogers EM. Diffusion of Innovations, 5th Edition. New York, NY: Free Press; 1995.

27. Troiano RP, Berrigan D, Dodd KW, Masse LC, Tilert T, McDowell M. Physical activity in the United States measured by accelerometer. Med Sci Sports Exerc. 2008;40(1):181-8.

28. Matthews CE, Chen KY, Freedson PS, Buchowski MS, Beech BM, Pate RR, et al. Amount of time spent in sedentary behaviors in the United States, 2003-2004. Am J Epidemiol. 2008;167(7):875-81. doi: 10.1093/aje/kwm390

29. UNC Lineberger Comprehensive Cancer Center. What is CHART? Chapel Hill, NC. https://chart.unc.edu/. Accessed May 10, 2017.

30. Craig CL, Marshall AL, Sjostrom M, Bauman AE, Booth ML, Ainsworth BE, et al. International physical activity questionnaire: 12-country reliability and validity. Med Sci Sports Exerc. 2003;35(8):1381-95. doi:

10.1249/01.MSS.0000078924.61453.FB

31. Thompson FE, Midthune D, Subar AF, McNeel T, Berrigan D, Kipnis V. Dietary intake estimates in the National Health Interview Survey, 2000: methodology, results, and interpretation. J Am Diet Assoc. 2005;105(3):352-63. doi: $10.1016 / j$.jada.2004.12.032

32. Centers for Disease Control and Prevention. Behavioral Risk Factor Surveillance System: BRFSS questionnaires. https://www.cdc.gov/brfss/questionnaires/index.htm. Accessed May 10, 2017.

33. Glasgow R, Emmons KM. The public health need for patient-reported measures and health behaviors in electronic health records: a policy statement of the Society of Behavioral Medicine. Transl Behav Med. 2011;1(1):108-9. doi: $10.1007 / \mathrm{s} 13142-011-0017-3$

34. Buysse DJ, Reynolds CF, 3rd, Monk TH, Berman SR, Kupfer DJ. The Pittsburgh Sleep Quality Index: a new instrument for psychiatric practice and research. Psychiatry Res. 1989;28(2):193-213.

35. Radloff LS. The CES-D scale: A self-report depression scale for research in the general population. Appl Psychol Meas. 1977;1(3):385-401. 
36. Centers for Disease Control and Prevention. National Health and Nutrition Examination Survey (NHANES): Anthropometry procedures manual. Atlanta, GA2013.

37. Pickering TG, Hall JE, Appel LJ, Falkner BE, Graves J, Hill MN, et al. Recommendations for blood pressure measurement in humans and experimental animals: Part 1: blood pressure measurement in humans: a statement for professionals from the Subcommittee of Professional and Public Education of the American Heart Association Council on High Blood Pressure Research. Hypertension. 2005;45(1):142-61. doi: 10.1161/01.HYP.0000150859.47929.8e

38. American Thoracic Society. Guidelines for the six-minute walk test. Am J Respir Crit Care Med. 2003;166:111-7. doi: 10.1164/ajrccm.166.1.at1102

39. Roberts HC, Denison HJ, Martin HJ, Patel HP, Syddall H, Cooper C, et al. A review of the measurement of grip strength in clinical and epidemiological studies: towards a standardised approach. Age Ageing. 2011;40(4):4239. doi: 10.1093/ageing/afr051

40. Jones CJ, Rikli RE, Beam WC. A 30-s chair-stand test as a measure of lower body strength in community-residing older adults. Res Q Exerc Sport. 1999;70(2):113-9. doi: 10.1080/02701367.1999.10608028

41. Centers for Disease Control and Prevention. The 30-second chair stand test. STEADI: Stopping Elderly Accidents, Deaths, \& Injuries, Atlanta, GA. 2013

http://www.cdc.gov/homeandrecreationalsafety/pdf/steadi/30_second_chair_stand_test.pdf. Accessed February 5, 2015.

42. Rossiter-Fornoff JE, Wolf SL, Wolfson LI, Buchner DM. A cross-sectional validation study of the FICSIT common data base static balance measures. Frailty and Injuries: Cooperative Studies of Intervention Techniques. J Gerontol A Biol Sci Med Sci. 1995;50(6):M291-7.

43. Centers for Disease Control and Prevention. The 4-stage balance test. STEADI: Stopping Elderly Accidents, Deaths \& Injuries, Atlanta, GA. 2013 https://www.cdc.gov/steadi/pdf/4-stage_balance_test-a.pdf. Accessed May $10,2017$.

44. Centers for Disease Control and Prevention, National Center for Chronic Disease Prevention and Health Promotion, Division for Heart Disease and Stroke Prevention. The CDC Worksite Health ScoreCard: An Assessment Tool for Employees to Prevent Heart Disease, Stroke, and Related Conditions. 2014 http://www.cdc.gov/dhdsp/pubs/worksite_scorecard.htm. Accessed March 24, 2017.

45. Department of Health Services, Division of Public Health, Nutrition, Physical Activity and Obesity Program, Wisconsin Nutrition, Physical Activity and Obesity Program. Worksite Wellness Resource Kit. 2010 https://www.dhs.wisconsin.gov/physical-activity/worksite/kit.htm. Accessed May 10, 2017.

46. Abrams DB, Boutwell WB, Grizzle J, Heimendinger J, Sorensen G, Varnes J. Cancer control at the workplace: the Working Well Trial. Prev Med. 1994;23(1):15-27.

47. Hipp JA, Reeds DN, van Bakergem MA, Marx CM, Brownson RC, Pamulapati SC, et al. Review of measures of worksite environmental and policy supports for physical activity and healthy eating. Prev Chronic Dis. 2015;12:E65. doi: 10.5888/pcd12.140410

48. Terry PE. Workplace Health Promotion Is Growing Up but Confusion Remains About What Constitutes a Comprehensive Approach. Am J Health Promot. 2019:890117119854618. doi: 10.1177/0890117119854618

49. Goetzel RZ, Henke RM, Tabrizi M, Pelletier KR, Loeppke R, Ballard DW, et al. Do workplace health promotion (wellness) programs work? J Occup Environ Med. 2014;56(9):927-34. doi: 10.1097/jom.0000000000000276

50. J. G. HERO Position Paper on the Value of Wellness Initiatives: How to Assess the evidence on "What Works". HERO; 2018. 
51. Otten JJ, Bradford VA, Stover B, Hill HD, Osborne C, Getts K, et al. The Culture Of Health In Early Care And Education: Workers' Wages, Health, And Job Characteristics. 2019;38(5):709-20. doi:

10.1377/hlthaff.2018.05493

52. Gratz RR, Claffey A. Adult health in child care: Health status, behaviors, and concerns of teachers, directors, and family child care providers. Early Child Res Q. 1996;11:243-67.

53. Sorensen G, McLellan DL, Sabbath EL, Dennerlein JT, Nagler EM, Hurtado DA, et al. Integrating worksite health protection and health promotion: A conceptual model for intervention and research. Prev Med. 2016;91:188-96. doi: 10.1016/j.ypmed.2016.08.005

54. Sorensen G, McLellan D, Dennerlein JT, Pronk NP, Allen JD, Boden LI, et al. Integration of health protection and health promotion: rationale, indicators, and metrics. J Occup Environ Med. 2013;55(12 Suppl):S12-8. doi: 10.1097/jom.0000000000000032

55. NIOSH. What is Total Worker Health? https://www.cdc.gov/niosh/twh/. Accessed 07/01, 2019.

56. Schwatka NV, Tenney L, Dally MJ, Scott J, Brown CE, Weitzenkamp D, et al. Small business Total Worker Health: A conceptual and methodological approach to facilitating organizational change. Occupational health science. 2018;2(1):25-41. doi: 10.1007/s41542-018-0013-9

57. Thompson J, Schwatka NV, Tenney L, Newman LS. Total Worker Health: A Small Business Leader Perspective. Int J Environ Res Public Health. 2018;15(11). doi: 10.3390/ijerph15112416

58. Rongen A, Robroek SJ, van Lenthe FJ, Burdorf A. Workplace health promotion: a meta-analysis of effectiveness. Am J Prev Med. 2013;44(4):406-15. doi: 10.1016/j.amepre.2012.12.007

\section{Tables}

Table 1. Baseline characteristics of workers and centers participating in the CARE study 


\section{Characteristics}

\section{Workers}

Female (\%)

Age (years, $\mathrm{M} \pm \mathrm{SD}$ )

Race and ethnicity (\%)

Non-Hispanic White

Non-Hispanic Black

Non-Hispanic Other

Hispanic

Annual household income (\%)

$$
\begin{aligned}
& <\$ 20 \mathrm{~K} \\
& >\$ 20 \mathrm{~K}
\end{aligned}
$$

Highest level of education (\%)

High school diploma/GED

Some college

Associate degree

Bachelor's degree

Graduate, MS, or higher

Married/Living with a partner (\%)

Household size (no. in household, $\mathrm{M} \pm \mathrm{SD}$ )

Health insured (\%)

Role at center (\%)

Administrator

Staff

Centers

Years in operation $(\mathrm{M} \pm \mathrm{SD})$

Hours per day of operation ( $\mathrm{M} \pm \mathrm{SD}$ )

Enrollment fee (\$/week, $\mathrm{M} \pm \mathrm{SD}$ )

Size

$$
\begin{aligned}
& \text { \# of children }(\mathrm{M} \pm \mathrm{SD}) \\
& \text { \# of employees }(\mathrm{M} \pm \mathrm{SD})
\end{aligned}
$$

Star rating $(\mathrm{M} \pm \mathrm{SD})$

Privately owned (\%)

Faith-based (\%)

Early Head Start (\%)

Accepts subsidies (\%)

Participates in CACFP (\%)

NAEYC accredited (\%)

\section{Healthy Lifestyles}

$\mathrm{n}=\mathbf{2 5 0}$

98.8

$40.0 \pm 13.1$

39.4

49.8

5.2

5.6

49.1

50.9

11.6

36.8

25.6

22.8

3.2

52.0

$3.2 \pm 1.6$

74.4

21.6

78.4

$\mathrm{n}=28$

$21.0 \pm 14.2$

$12.7 \pm 3.3$

$142.4 \pm 19.9$

$67.1 \pm 34.7$

$14.4 \pm 8.1$

$4.3 \pm 0.6$

78.6

17.9

3.6

96.4

85.7

21.4
12.3

15.6

34.6

53.2

5.7

6.6

41.0

59.0

37.4

26.5

18.5

5.3

52.2

$3.3 \pm 1.7$

79.8

84.5

$\mathrm{n}=28$

$15.5 \pm 8.3$

$13.0 \pm 2.7$

$141.0 \pm 17.8$

Note: $\mathrm{M}=$ mean, $\mathrm{SD}=$ standard deviation, GED = General Education Diploma, $\mathrm{MS}=$ Master of Science,

$65.7 \pm 37.6$

$15.0 \pm 10.3$

$4.4 \pm 0.8$

64.3

35.7

100

89.3

17.9 
CACFP $=$ Child and Adult Care Food Program, NAEYC $=$ National Association for the Education of Young Children

Page 18/23 
Table 2. Changes in providers' physical activity and other health outcomes.

\begin{tabular}{|c|c|c|c|c|c|c|c|c|c|c|}
\hline \multirow[b]{3}{*}{ Outcome } & \multicolumn{3}{|c|}{ Healthy Lifestyle } & \multicolumn{3}{|c|}{ Healthy Finance } & \multirow{3}{*}{$\begin{array}{l}\text { Diff in } \\
\text { mean } \\
\text { change }\end{array}$} & \multirow[b]{2}{*}{ Adj. } & \multirow[b]{3}{*}{ ICC } & \multirow[b]{3}{*}{ ES } \\
\hline & \multirow{2}{*}{$\begin{array}{l}\text { Baseline } \\
\text { mean } \\
\text { (SD) }\end{array}$} & \multirow{2}{*}{$\begin{array}{l}\text { Change } \\
\text { mean }(\mathrm{CI})\end{array}$} & \multirow{2}{*}{$\begin{array}{c}\text { Adj. } \\
\text { p-value }\end{array}$} & \multirow{2}{*}{$\begin{array}{c}\text { Baseline } \\
\text { mean } \\
\text { (SD) }\end{array}$} & \multirow{2}{*}{$\begin{array}{l}\text { Change } \\
\text { mean }(\mathrm{CI})\end{array}$} & \multirow{2}{*}{$\begin{array}{c}\text { Adj. } \\
\text { p- } \\
\text { value }\end{array}$} & & & & \\
\hline & & & & & & & & $\begin{array}{c}\text { p- } \\
\text { value }\end{array}$ & & \\
\hline Primary Outcome & & & & & & & & & & \\
\hline MVPA (min/day) ${ }^{1}$ & $\begin{array}{c}16.0 \\
(13.4)\end{array}$ & $\begin{array}{l}-1.3(-3.0 \\
0.3)^{*}\end{array}$ & - & $\begin{array}{c}18.6 \\
(14.8)\end{array}$ & $\begin{array}{c}-1.9(-3.3 \\
-0.5)^{* *}\end{array}$ & - & $\begin{array}{c}0.6 \\
(-1.6 \\
2.8)\end{array}$ & - & 0.00 & 0.04 \\
\hline Secondary Outcomes & & & & & & & & & & \\
\hline $\begin{array}{l}\text { Additional Physical } \\
\text { Activity Outcomes }\end{array}$ & & & & & & & & & & \\
\hline Lifestyle MVPA $^{1}$ & $\begin{array}{l}117.0 \\
(47.7)\end{array}$ & $\begin{array}{c}-4.7 \\
(-10.3 \\
1.0)^{*}\end{array}$ & 0.05 & $\begin{array}{l}124.5 \\
(49.7)\end{array}$ & $\begin{array}{c}-4.2(-8.9 \\
0.6)\end{array}$ & 0.09 & $\begin{array}{l}-0.5 \\
(-7.9 \\
6.9)\end{array}$ & 0.95 & 0.02 & 0.01 \\
\hline $\begin{array}{l}\text { Weekday MVPA } \\
(\min / \text { day })^{1}\end{array}$ & $\begin{array}{c}16.9 \\
(14.1)\end{array}$ & $\begin{array}{c}-1.9(-3.8 \\
-0.1)^{* *}\end{array}$ & 0.04 & $\begin{array}{c}20.3 \\
(17.1)\end{array}$ & $\begin{array}{l}-2.9(-4.5 \\
-1.3) * * *\end{array}$ & $<0.001$ & $\begin{array}{c}1.0 \\
(-1.5 \\
3.4)\end{array}$ & 0.95 & 0.00 & 0.06 \\
\hline $\begin{array}{l}\text { Weekend MVPA } \\
(\min / \text { day })^{1}\end{array}$ & $\begin{array}{c}12.1 \\
(15.7)\end{array}$ & $\begin{array}{l}0.3(-2.5 \\
3.1)\end{array}$ & 0.66 & $\begin{array}{c}13.1 \\
(13.3)\end{array}$ & $\begin{array}{l}0.9(-1.5 \\
3.3)\end{array}$ & 0.66 & $\begin{array}{l}-0.6 \\
(-4.3 \\
3.1)\end{array}$ & 0.96 & 0.01 & 0.04 \\
\hline $\begin{array}{c}\text { Meets PA } \\
\text { recommendation } \\
(150 \mathrm{~min} / \mathrm{wk} .)^{2,3}\end{array}$ & $\begin{array}{c}57 \\
(25.7)\end{array}$ & $\begin{array}{c}0.63 \\
(0.44 \\
0.92)^{*}\end{array}$ & 0.04 & $\begin{array}{c}93 \\
(32.6)\end{array}$ & $\begin{array}{c}0.69 \\
(0.52 \\
0.93)^{*}\end{array}$ & 0.04 & $\begin{array}{l}0.92 \\
(0.57 \\
1.46)\end{array}$ & 0.95 & 0.00 & 0.03 \\
\hline
\end{tabular}

\section{Dietary Intake}

\begin{tabular}{|c|c|c|c|c|c|c|c|c|c|c|}
\hline Whole fruit & $0.7(0.6)$ & $\begin{array}{c}0.1(-0.02 \\
0.2)\end{array}$ & 0.13 & $0.8(0.7)$ & $\begin{array}{c}-0.1(-0.2 \\
0.01)\end{array}$ & 0.15 & $\begin{array}{c}0.2 \\
(0.02 \\
0.3)^{*}\end{array}$ & 0.10 & 0.01 & 0.30 \\
\hline $\begin{array}{l}\quad \text { Vegetable } \\
\text { (excluding potatoes) }^{1}\end{array}$ & $1.0(0.7)$ & $\begin{array}{c}0.1(0.03 \\
0.3)^{*}\end{array}$ & 0.04 & $1.0(0.8)$ & $\begin{array}{l}-0.02 \\
(-0.1 \\
0.1)^{*}\end{array}$ & 0.05 & $\begin{array}{c}0.2 \\
(0.01 \\
0.3)^{*}\end{array}$ & 0.10 & 0.02 & 0.26 \\
\hline $\begin{array}{l}\quad \text { Fruits } \\
\text { \&vegetables } \\
\text { (excluding potatoes } \\
\text { and juice) }{ }^{1}\end{array}$ & $1.6(1.1)$ & $\begin{array}{c}0.2(0.04 \\
0.4)^{*}\end{array}$ & 0.04 & $1.8(1.2)$ & $\begin{array}{c}-0.1(-0.3 \\
0.1)\end{array}$ & 0.26 & $\begin{array}{c}0.3(0.1 \\
0.6)^{* *}\end{array}$ & 0.06 & 0.02 & 0.26 \\
\hline $\begin{array}{l}\text { Sugar sweetened } \\
\text { beverage }^{1}\end{array}$ & $1.8(1.9)$ & $\begin{array}{l}-0.5(-0.8 \\
-0.2) * * *\end{array}$ & $<0.001$ & $1.6(1.8)$ & $\begin{array}{c}-0.2(-0.5 \\
0.03)\end{array}$ & 0.15 & $\begin{array}{l}-0.3 \\
(-0.7 \\
0.1)^{*}\end{array}$ & 0.11 & 0.01 & 0.16 \\
\hline Salty snack ${ }^{1}$ & $1.3(1.5)$ & $\begin{array}{l}-0.5(-0.7 \\
-0.2) * * *\end{array}$ & $<0.001$ & $1.4(1.8)$ & $\begin{array}{c}-0.3(-0.5 \\
-0.0)^{* *}\end{array}$ & 0.02 & $\begin{array}{c}-0.2 \\
(-0.5 \\
0.2)\end{array}$ & 0.32 & 0.00 & 0.12 \\
\hline $\begin{array}{l}\text { Fast food/ Eating } \\
\text { out }^{1}\end{array}$ & $0.4(0.4)$ & $\begin{array}{l}-0.1(-0.2 \\
-0.1) * * *\end{array}$ & $<0.001$ & $0.3(0.3)$ & $\begin{array}{c}-0.1(-0.1 \\
-0.1)^{*}\end{array}$ & 0.04 & $\begin{array}{c}-0.1 \\
(-0.1 \\
-0.02)^{* *}\end{array}$ & 0.06 & 0.00 & 0.28 \\
\hline $\begin{array}{l}\text { Eating Habits } \\
\text { Score }\end{array}$ & $9.1(3.3)$ & $\begin{array}{l}1.2(0.8 \\
1.8) * * *\end{array}$ & $<0.001$ & $9.6(3.4)$ & $\begin{array}{c}0.4(-0.1 \\
0.8)\end{array}$ & 0.15 & $\begin{array}{c}0.9(0.2 \\
1.6)^{* *}\end{array}$ & 0.06 & 0.00 & 0.27 \\
\hline
\end{tabular}

Tobacco and e-

cigarette Use

Smoking status

$38 \quad 0.66 \quad 0.03$

$\begin{array}{lllllll}40 & 1.05(0.81, & 0.74 & 0.6(0.4, & 0.10 & 0.04 & 0.04\end{array}$

Page 19/23 


\begin{tabular}{|c|c|c|c|c|c|c|c|c|c|c|}
\hline $\begin{array}{l}\text { (current smoke/non- } \\
\text { smoker) }{ }^{2,3}\end{array}$ & $(15.2)$ & $\begin{array}{l}(0.46, \\
0.92)^{*}\end{array}$ & & (13.3) & 1.37) & & $1.0)^{*}$ & & & \\
\hline $\begin{array}{c}\text { E-cig use (ever } \\
\text { used/never used) } \\
\text { us, }\end{array}$ & $\begin{array}{c}25 \\
(10.0)\end{array}$ & $\begin{array}{c}0.73 \\
(0.45 \\
1.20)\end{array}$ & 0.24 & $28(9.3)$ & $\begin{array}{c}0.68 \\
(0.40 \\
1.19)\end{array}$ & 0.25 & $\begin{array}{c}1.1(0.5, \\
2.2)\end{array}$ & 0.87 & 0.04 & 0.11 \\
\hline
\end{tabular}

\section{Sleep}

\begin{tabular}{|c|c|c|c|c|c|c|c|c|c|c|}
\hline Hours/night & $6.3(1.4)$ & $\begin{array}{c}0.4(0.2 \\
0.5)^{* *}\end{array}$ & $<0.001$ & $6.4(1.4)$ & $\begin{array}{c}0.1(-0.1 \\
0.3)\end{array}$ & 0.31 & $\begin{array}{c}0.3 \\
(0.01 \\
0.5)^{*}\end{array}$ & 0.11 & 0.03 & 0.21 \\
\hline $\begin{array}{l}\text { Quality } \\
\text { od/bad) } 2,3\end{array}$ & $\begin{array}{c}190 \\
(76.0)\end{array}$ & $\begin{array}{c}1.38 \\
(0.99 \\
1.92)\end{array}$ & 0.07 & $\begin{array}{c}236 \\
(78.4)\end{array}$ & $\begin{array}{l}0.98 \\
(0.76 \\
1.26)\end{array}$ & 0.87 & $\begin{array}{c}1.4(0.9 \\
2.1)\end{array}$ & 0.20 & 0.03 & 0.02 \\
\hline
\end{tabular}

\section{Stress}

\begin{tabular}{|c|c|c|c|c|c|c|c|c|c|c|}
\hline $\begin{array}{l}\text { Perceived level of } \\
\text { distress }\end{array}$ & $3.9(2.7)$ & $\begin{array}{c}-1.2(-1.6 \\
-0.7) * * *\end{array}$ & $<0.001$ & $4.0(2.8)$ & $\begin{array}{c}-0.7(-1.1 \\
-0.3)^{*}\end{array}$ & $<0.01$ & $\begin{array}{l}-0.5 \\
(-1.1 \\
0.1)\end{array}$ & 0.20 & 0.00 & 0.18 \\
\hline \multicolumn{11}{|l|}{$\begin{array}{l}\text { Health and Fitness } \\
\text { Indicators }\end{array}$} \\
\hline BMI $\left(\mathrm{kg} / \mathrm{m}^{2}\right)$ & $\begin{array}{l}33.7 \\
(9.1)\end{array}$ & $\begin{array}{c}0.1(-0.2 \\
0.4)\end{array}$ & 0.39 & $\begin{array}{l}34.2 \\
(8.8)\end{array}$ & $\begin{array}{l}0.0(-0.2 \\
0.3)\end{array}$ & 0.82 & $\begin{array}{c}0.1 \\
(-0.3 \\
0.5)\end{array}$ & 0.78 & 0.02 & 0.01 \\
\hline $\begin{array}{l}\text { Mean arterial } \\
\text { pressure }\end{array}$ & $\begin{array}{c}94.2 \\
(14.0)\end{array}$ & $\begin{array}{c}-1.8(-3.5 \\
-0.1)^{*}\end{array}$ & 0.05 & $\begin{array}{c}95.0 \\
(13.2)\end{array}$ & $\begin{array}{c}-3.6(-5.1 \\
-2.2) * * *\end{array}$ & $<0.001$ & $\begin{array}{l}0.8 \\
(-0.4 \\
4.0)\end{array}$ & 0.20 & 0.07 & 0.06 \\
\hline Grip strength (kg) & $\begin{array}{l}26.3 \\
(9.3)\end{array}$ & $\begin{array}{c}1.9(0.4 \\
3.5)^{*}\end{array}$ & 0.03 & $\begin{array}{l}28.5 \\
(9.1)\end{array}$ & $\begin{array}{c}1.6(0.3 \\
2.9)\end{array}$ & 0.04 & $\begin{array}{c}0.3 \\
(-1.7 \\
2.4)\end{array}$ & 0.86 & 0.07 & 0.03 \\
\hline $\begin{array}{l}\text { Chair sit and stand } \\
\text { (reps) }\end{array}$ & $\begin{array}{l}14.9 \\
(4.3)\end{array}$ & $\begin{array}{l}-1.5(-2.2 \\
-0.8) * * *\end{array}$ & $<0.001$ & $\begin{array}{l}15.2 \\
(4.6)\end{array}$ & $\begin{array}{l}-1.3(-1.8 \\
-0.7) * * *\end{array}$ & $<0.001$ & $\begin{array}{c}-0.2 \\
(-1.1 \\
0.7)\end{array}$ & 0.78 & 0.08 & 0.04 \\
\hline $\begin{array}{l}\quad \text { Highest phase } \\
\text { completed in balance } \\
\text { test }^{2,3}\end{array}$ & $\begin{array}{c}99 \\
(76.7)\end{array}$ & $\begin{array}{l}1.01 \\
(0.68 . \\
1.52)\end{array}$ & 0.93 & $\begin{array}{c}151 \\
(77.4)\end{array}$ & $\begin{array}{l}1.11 \\
(0.67 \\
1.86)\end{array}$ & 0.74 & $\begin{array}{c}0.9(0.5 \\
1.7)\end{array}$ & 0.86 & 0.01 & 0.01 \\
\hline
\end{tabular}

\section{Teacher Physical}

Activity Practices

\begin{tabular}{|c|c|c|c|c|c|c|c|c|c|c|}
\hline $\begin{array}{l}\text { Total min PA } \\
\text { provided }^{1}\end{array}$ & $\begin{array}{c}170.8 \\
(122.3)\end{array}$ & $\begin{array}{c}-10.5 \\
(-33.9 \\
13.0)\end{array}$ & 0.87 & $\begin{array}{c}162.7 \\
(117.0)\end{array}$ & $\begin{array}{c}5.3(-14.9, \\
25.5)\end{array}$ & 0.70 & $\begin{array}{c}-15.7 \\
(-46.7 \\
15.2)\end{array}$ & 0.71 & 0.07 & 0.13 \\
\hline $\begin{array}{l}\text { Total min teacher- } \\
\text { led } \mathrm{PA}^{1}\end{array}$ & $\begin{array}{c}70.4 \\
(55.9)\end{array}$ & $\begin{array}{c}-2.5 \\
(-16.9 \\
12.0)\end{array}$ & 0.87 & $\begin{array}{c}67.4 \\
(69.2)\end{array}$ & $\begin{array}{c}-0.1 \\
(-12.3 \\
12.3)\end{array}$ & 0.73 & $\begin{array}{c}-2.4 \\
(-21.4 \\
16.6)\end{array}$ & 0.71 & 0.00 & 0.04 \\
\hline $\begin{array}{l}\text { Outside time as } \\
\text { reward score }\end{array}$ & $3.4(0.7)$ & $\begin{array}{c}-0.0(-0.2 \\
0.1)\end{array}$ & 0.87 & $3.4(0.7)$ & $\begin{array}{c}-0.0(-0.1 \\
0.1)\end{array}$ & 0.88 & $\begin{array}{c}-0.0 \\
(-0.2 \\
0.2)\end{array}$ & 0.99 & 0.00 & 0.00 \\
\hline $\begin{array}{l}\text { TV as reward } \\
\text { score }^{2,3}\end{array}$ & $\begin{array}{c}165 \\
(72.1)\end{array}$ & $\begin{array}{c}1.31(0.89, \\
1.90)\end{array}$ & 0.48 & $\begin{array}{c}119 \\
(67.2)\end{array}$ & $\begin{array}{c}0.74 \\
(0.48 \\
1.12)\end{array}$ & 0.33 & $\begin{array}{c}1.77 \\
(1.01 \\
3.12)\end{array}$ & 0.41 & 0.13 & 0.03 \\
\hline Praise PA score ${ }^{2,3}$ & $\begin{array}{c}82 \\
(46.3)\end{array}$ & $\begin{array}{l}1.02 \\
(0.78 \\
1.34)\end{array}$ & 0.87 & $\begin{array}{c}90 \\
(39.5)\end{array}$ & $\begin{array}{l}1.21 \\
(0.88 \\
1.66)\end{array}$ & 0.36 & $\begin{array}{c}0.85 \\
(0.56 \\
1.29)\end{array}$ & 0.71 & 0.00 & 0.02 \\
\hline
\end{tabular}

Page 20/23 


\begin{tabular}{|c|c|c|c|c|c|c|c|c|c|c|}
\hline & & & & & & & $0.1)$ & & & \\
\hline $\begin{array}{l}\text { Encourage/Prompt } \\
\text { PA score }\end{array}$ & $3.9(0.7)$ & $\begin{array}{c}-0.0(-0.1 \\
0.1)\end{array}$ & 0.87 & $3.9(0.7)$ & $\begin{array}{l}0.1(-0.0 \\
0.2)\end{array}$ & 0.36 & $\begin{array}{c}-0.1 \\
(-0.2 \\
0.1)\end{array}$ & 0.71 & 0.04 & 0.14 \\
\hline
\end{tabular}

1 Square root transformation of the outcomes were used for analyses and thus providing valid p-values, however, results are presented in their original scale

2 Results for baseline are presented as $\mathrm{n}(\%)$

3 Results for change are presented as OR (95\% CI)

Table 3. Changes in child care centers' workplace health and safety environmental supports.

\begin{tabular}{|c|c|c|c|c|c|c|c|c|c|}
\hline \multirow[b]{3}{*}{ Outcome } & \multicolumn{3}{|c|}{ Healthy Lifestyle } & \multicolumn{3}{|c|}{ Healthy Finance } & \multirow{3}{*}{$\begin{array}{l}\text { Diff in mean } \\
\text { change }\end{array}$} & \multirow[b]{2}{*}{ Adj. } & \multirow[b]{3}{*}{ ES } \\
\hline & \multirow{2}{*}{$\begin{array}{c}\text { Baseline } \\
\text { mean } \\
(\mathrm{SD})\end{array}$} & \multirow{2}{*}{$\begin{array}{l}\text { Change } \\
\text { mean }(\mathrm{CI})\end{array}$} & \multirow{2}{*}{$\begin{array}{c}\text { Adj. } \\
\text { p- } \\
\text { value }\end{array}$} & \multirow{2}{*}{$\begin{array}{c}\text { Baseline } \\
\text { mean } \\
\text { (SD) }\end{array}$} & \multirow{2}{*}{$\begin{array}{l}\text { Change } \\
\text { mean }(\mathrm{CI})\end{array}$} & \multirow{2}{*}{$\begin{array}{c}\text { Adj. } \\
\text { p- } \\
\text { value }\end{array}$} & & & \\
\hline & & & & & & & & $\begin{array}{c}\text { p- } \\
\text { value }\end{array}$ & \\
\hline Worksite Health and Safety & $\begin{array}{c}41.8 \\
(11.9)\end{array}$ & $\begin{array}{c}0.9(-4.1 \\
5.9)\end{array}$ & 0.71 & $\begin{array}{c}44.0 \\
(13.1)\end{array}$ & $\begin{array}{c}1.0(-2.5 \\
4.4)\end{array}$ & 0.91 & $\begin{array}{c}-0.0(-6.0 \\
5.9)\end{array}$ & 0.99 & 0.00 \\
\hline Infrastructure score & $\begin{array}{c}9.7 \\
(4.2)\end{array}$ & $\begin{array}{c}-0.8 \\
(-2.7,1.1)\end{array}$ & 0.54 & $\begin{array}{c}9.8 \\
(3.7)\end{array}$ & $\begin{array}{c}0.1 \\
(-1.7,1.9)\end{array}$ & 0.91 & $\begin{array}{c}-0.9 \\
(-3.5,1.7)\end{array}$ & 0.85 & 0.22 \\
\hline $\begin{array}{l}\text { Organization Policies \& } \\
\text { Procedures (OPP) }\end{array}$ & $\begin{array}{l}11.5 \\
(3.6)\end{array}$ & $\begin{array}{l}1.5(0.4 \\
2.6)^{*}\end{array}$ & 0.04 & $\begin{array}{l}12.3 \\
(4.1)\end{array}$ & $\begin{array}{l}0.7(-0.5 \\
2.0)\end{array}$ & 0.91 & $\begin{array}{l}0.8(-0.9 \\
2.4)\end{array}$ & 0.85 & 0.21 \\
\hline OPP - Physical activity & $\begin{array}{c}1.6 \\
(1.0)\end{array}$ & $\begin{array}{c}1.0(0.5 \\
1.5)^{* * *}\end{array}$ & $<0.01$ & $\begin{array}{c}2.1 \\
(1.3)\end{array}$ & $\begin{array}{l}0.4(-0.1 \\
0.8)\end{array}$ & 0.91 & $\begin{array}{l}0.6(0.01 \\
1.3)^{*}\end{array}$ & 0.26 & 0.52 \\
\hline Programs \& Promotions (PP) & $\begin{array}{c}7.4 \\
(5.0)\end{array}$ & $\begin{array}{l}0.6(-1.9 \\
3.0)\end{array}$ & 0.70 & $\begin{array}{c}8.4 \\
(5.8)\end{array}$ & $\begin{array}{l}0.2(-1.3 \\
1.7)\end{array}$ & 0.91 & $\begin{array}{l}0.4(-2.5 \\
3.2)\end{array}$ & 0.98 & 0.07 \\
\hline PP - Physical activity & $\begin{array}{c}0.5 \\
(0.8)\end{array}$ & $\begin{array}{l}0.8(0.3 \\
1.3)^{* *}\end{array}$ & 0.01 & $\begin{array}{c}0.5 \\
(1.0)\end{array}$ & $\begin{array}{l}0.1(-0.3 \\
0.4)\end{array}$ & 0.91 & $\begin{array}{l}0.7(0.1 \\
1.3)^{*}\end{array}$ & 0.11 & 0.77 \\
\hline $\begin{array}{l}\text { Internal Physical } \\
\text { Environment (IPE) }\end{array}$ & $\begin{array}{l}13.2 \\
(1.8)\end{array}$ & $\begin{array}{c}-0.3(-1.2 \\
0.6)\end{array}$ & 0.65 & $\begin{array}{l}13.5 \\
(2.2)\end{array}$ & $\begin{array}{c}-0.1(-0.8 \\
0.7)\end{array}$ & 0.91 & $\begin{array}{c}-0.2(-1.4 \\
1.0)\end{array}$ & 0.98 & 0.10 \\
\hline IPE - Physical activity & $\begin{array}{c}0.7 \\
(0.9)\end{array}$ & $\begin{array}{l}0.4(-0.0 \\
0.8)\end{array}$ & 0.14 & $\begin{array}{c}0.9 \\
(1.1)\end{array}$ & $\begin{array}{c}0.1(-0.2 \\
0.4)\end{array}$ & 0.91 & $\begin{array}{c}0.3(-0.2 \\
0.8)\end{array}$ & 0.85 & 0.30 \\
\hline
\end{tabular}

$\mathrm{SD}=$ standard deviation, $\mathrm{CI}=$ confidence interval, $\mathrm{Adj} .=$ adjusted

Unadjusted significance $* \mathrm{p}<0.05, * * \mathrm{p}<0.01, * * * \mathrm{p}<0.001$.

Table 4. Intervention Delivery and Participation 


\begin{tabular}{|c|c|c|}
\hline $\begin{array}{l}\text { Intervention } \\
\text { Component }\end{array}$ & Delivery by Research Team & $\begin{array}{l}\text { Participation by } \\
\text { Centers/Workers }\end{array}$ \\
\hline $\begin{array}{l}\text { Educational } \\
\text { workshops }\end{array}$ & $\begin{array}{l}7 \text { sessions offered as part of kick-off events; most waves were offered a } \\
\text { choice of } 2 \text { dates. }\end{array}$ & $\begin{array}{l}100 \% \text { of centers were } \\
\text { represented at workshops; } \\
\text { only } 54 \% \text { of workers attended }\end{array}$ \\
\hline Magazines & $\begin{array}{l}\text { Magazines were delivered during the first week of each campaign to all } 28 \\
\text { centers. }\end{array}$ & $\begin{array}{l}\text { No tracking of magazine } \\
\text { distribution to workers }\end{array}$ \\
\hline $\begin{array}{l}\text { Self- } \\
\text { monitoring }\end{array}$ & $\begin{array}{l}\text { Pedometers and website access were made available to } 100 \% \text { of workers } \\
\text { either during the educational workshop or a follow-up center visit (for those } \\
\text { who did not attend the workshop). }\end{array}$ & $\begin{array}{l}72 \% \text { of workers monitored at } \\
\text { least once }\end{array}$ \\
\hline Prompts & $\begin{array}{l}\text { Test accounts created by research staff monitored delivery of messages } 1 \\
\text { week ahead of time. All problems were either resolved prior to scheduled } \\
\text { distribution or prompts were sent manually. }\end{array}$ & $\begin{array}{l}\text { No tracking of delivery of } \\
\text { prompts to workers }\end{array}$ \\
\hline Feedback & Test accounts also used to monitor delivery of tailored feedback. & $\begin{array}{l}\text { No tracking of delivery of } \\
\text { prompts to workers }\end{array}$ \\
\hline Raffle & Raffles were completed for each wave and each campaign. & $\begin{array}{l}\text { Only } 44 \% \text { of workers qualified } \\
\text { for entry into at least one } \\
\text { raffle }\end{array}$ \\
\hline $\begin{array}{l}\text { Center } \\
\text { Visuals }\end{array}$ & $\begin{array}{l}\text { All } 28 \text { centers were provided with center visuals during the initial } \\
\text { workshop; and all } 28 \text { centers received updated materials at the beginning } \\
\text { of campaigns } 2 \text { and } 3 \text {. }\end{array}$ & $\begin{array}{l}67 \% \text { of centers had visuals } \\
\text { displayed when visited }\end{array}$ \\
\hline $\begin{array}{l}\text { Director } \\
\text { Coaching }\end{array}$ & $\begin{array}{l}\text { During wave } 1 \text { we hosted } 4 \text { webinars and invited all } 8 \text { directors in that wave } \\
\text { to attend. During waves } 2-4 \text {, all } 20 \text { directors were offered director coaching } \\
\text { calls. }\end{array}$ & $\begin{array}{l}\text { During wave } 1,100 \% \text { of } \\
\text { directors participated in at } \\
\text { least } 1 \text { webinar. } \\
\text { During wave } 2-4,100 \% \text { of } \\
\text { directors participated in at } \\
\text { least } 1 \text { coaching call }\end{array}$ \\
\hline
\end{tabular}

\section{Figures}




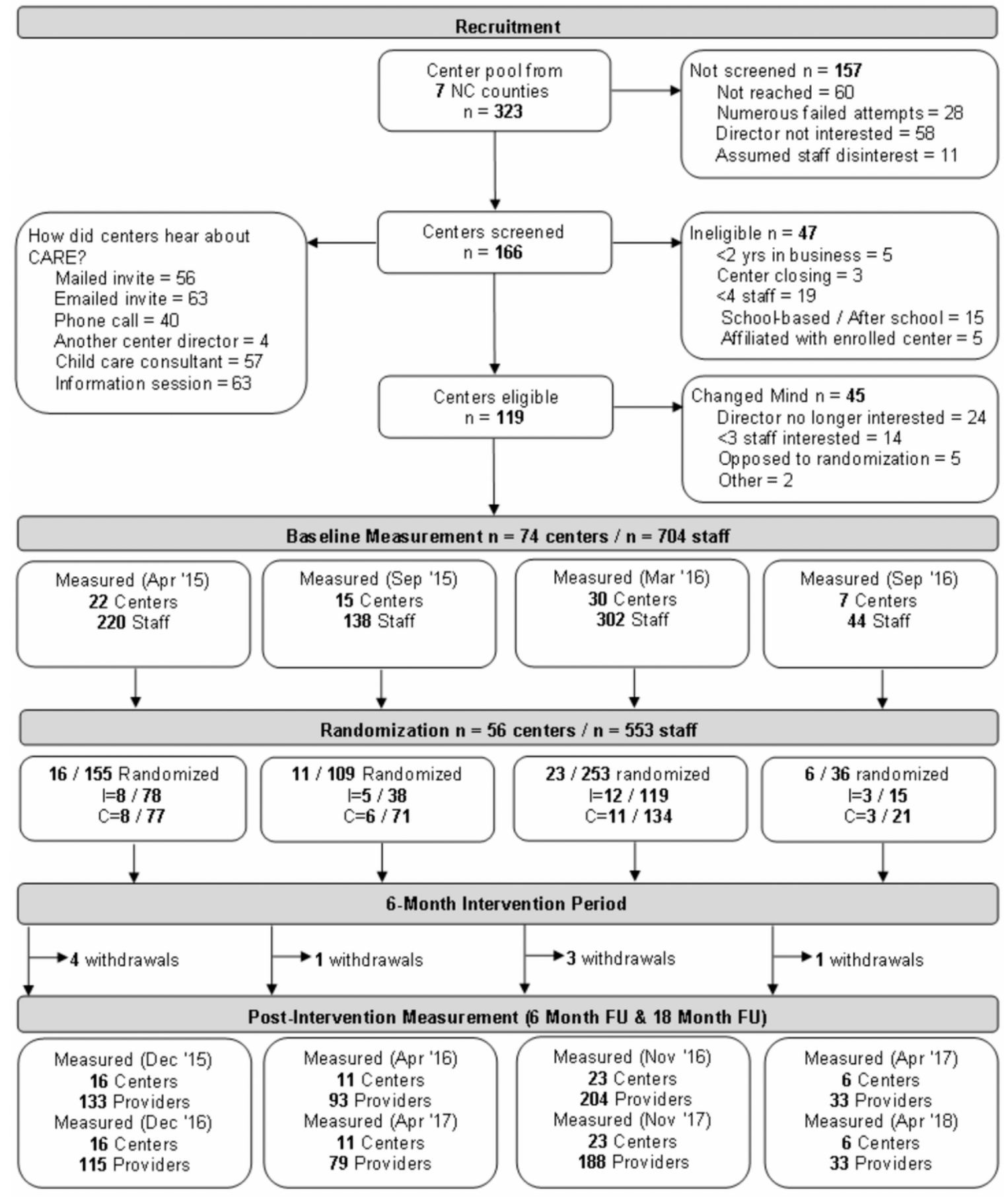

Figure 1

Consort Diagram 